\title{
POST-COVID-19 UNIVERSITY GOVERNANCE IN GERMANY
}

\author{
Jelena Zascerinska \\ Centre for Education and Innovation Research, Latvia
}

\begin{abstract}
Researchers admit that there will not be a quick return to "business as usual", especially related to internationalization, the financing of studies and universities, research and administration. The enabling research question is formulated as following: What is the relationship between the COVID-19 pandemic and university governance? The aim of the article is to examine the relationship between the COVID-19 pandemic and university governance underpinning the elaboration of implications for higher education. The study was of the qualitative nature. The exploratory study was implemented. The study was carried out in Germany on the 22nd September 2020. Focus group interview served as a method of data collection. The data were interpreted via structuring and summarising content analysis. The theoretical finding is that the COVID-19 pandemic is a factor that influences the university governance. The COVID-19 pandemic is an external factor in regard to university governance. Factor impact can be regulated. Factor impact can be increased or decreased according to the situation requirements. The empirical data allow concluding that the COVID-19 pandemic fastens the changes in governing the universities in Germany. Implications for higher education are presented. Research limitations are identified. Directions of further research are proposed. Keywords: COVID-19, higher education, Germany, governance, objectives, rules, university.
\end{abstract}

\section{Introduction}

The outbreak of COVID-19 in the world has led to the unprecedented changed in people's lives. Many people have experienced rapid transformations in many aspects of their lives: working conditions, shopping, travelling, finance, etc.

Higher education has also been significantly adapted to the new situation created by the COVID-19 pandemic. Higher education is conventionally delivered by higher education institutions. "Higher education institutions" and "universities" are used synonymously in this work.

The first university reaction to the COVID-19 pandemic in March 2020 was expressed by the full lockdown: university staff and students were not allowed entering university campus and premises. The corona lockdown has interrupted usual university processes in almost all areas, namely teaching, university management, laboratory work, etc. Then, in April 2020, face-to-face lectures were 
replaced by their digital equivalents. Since the global spread of the coronavirus pandemic, universities, as higher education providers, gradually shift their oncampus activities to the on-line performance. On-line lectures, department on-line meetings, student on-line project work are only some of the university measures in response to the COVID-19 pandemic.

Against this background, many researchers admit that probably there will not be a quick return to "business as usual", especially related to internationalization, the financing of studies and universities, research and administration.

The enabling research question is formulated as following: What is the relationship between the COVID-19 pandemic and university governance?

The aim of the article is to examine the relationship between the COVID-19 pandemic and university governance underpinning the elaboration of implications for higher education.

The study was of the qualitative nature. The exploratory study was implemented. The study was carried out in Germany on the 22 ${ }^{\text {nd }}$ September 2020. The focus group interview served as a method of data collection. The data were interpreted via structuring content analysis as well as summarising content analysis.

\section{Conceptual Framework}

University governance is defined as the constitutional forms and processes through which universities govern their affairs (Shattock, 2006). University's affairs at institutional level refer to

- teaching and

- learning,

- internationalization,

- the financing of studies and universities,

- research and

- $\quad$ administration as well as

- others.

University governance is opposed to university management. Figure 1 reflects the inter-relationship between university governance and university management.

University management ensures the implementation of university's constitutional forms and processes by which university's objectives are achieved.

University governance relies on university policies. University policies include guidelines, rules, and procedures established to support efforts and encourage work towards stated objectives (Aboy, 2018). 


\section{University governance}

University management

Figure 1 The relationship between university governance and university management

University governance is formed by factors. By factor, a reason of the phenomenon's change is meant. Factors are conventionally differentiated (Zaščerinska, Zaščerinskis, Andreeva, \&Aḷeksejeva, 2013), as shown in Figure 2, into external and internal.

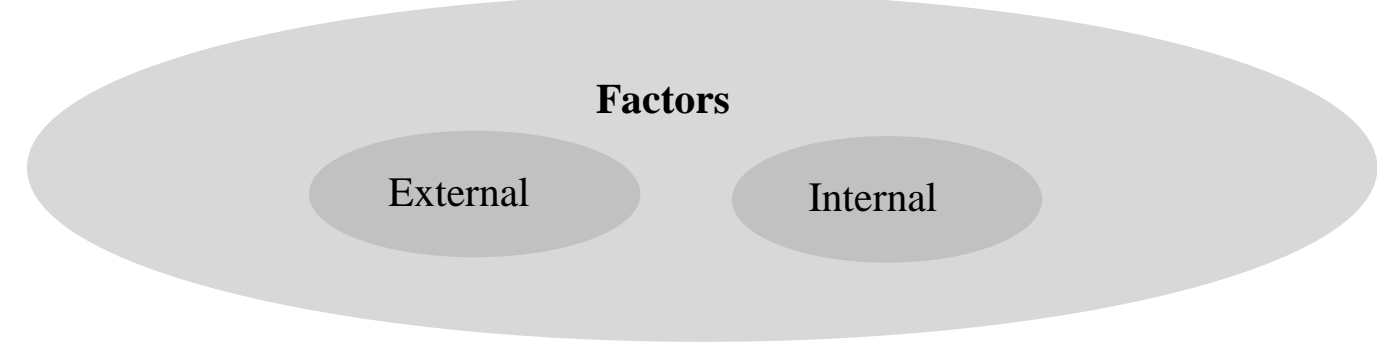

Figure 2 The relationship between factor, external factor and internal factor

The COVID-19 pandemic in this work is certainly an external factor that shapes university governance. It should be noted that, depending on the research focus, the COVID-19 pandemic can be also analysed as

- a research object,

- a criterion and indicator,

- a structural element, etc.

Identification of the COVID-19 pandemic as a factor leads to the research goal to mitigate or diminish the effect of the COVID-19 pandemic on universities.

Scientific literature addressed to analyse the decrease in the impact of the COVID-19 pandemic on universities reveals that there is no "right answer", no “one-size-fits-all” response (Peregrine, DeJong, DiVarco, McDermott \& Emery LLP, 2020). The ultimate consideration in play post-pandemic is the expectation that university governance policies and procedures will periodically be reevaluated in the light of their particular facts and circumstances (Peregrine, DeJong, DiVarco, McDermott \& Emery LLP, 2020).

There is a need to refocus thinking away from the short-term and urgent issues and look to the medium and long term (McVitty, 2020). Though each university may have its own internal discussions and scenarios, there's a loss of 
quality and efficiency of strategic thinking about the sector as a whole (McVitty, 2020). This is not only about institutional autonomy but about sourcing the best ideas and insight about the role of higher education in a post-Covid-19 world (McVitty, 2020).

Traditionally, effective governance has been framed as protecting the longevity and sustainability of one's own institution (McVitty, 2020). But governors can offer a strategic leadership on how education institutions can fulfil their mission to serve their place, as well (McVitty, 2020). The most appropriate approach is for the university governors to pursue such a self-analysis from a good faith, informed perspective (Peregrine, DeJong, DiVarco, McDermott \& Emery LLP, 2020).

Hence, the analysis of scientific literature results in findings that

- university governance changes due to particular facts and circumstances,

- the approach of self-analysis from the informed perspective should be practised,

- $\quad$ long term issues and sustainability should be prioritized, instead of dealing with the short-term and urgent issues,

- the focus should be put on the whole sector of higher education, but not on each university.

\section{Empirical Study Design}

The empirical study was enabled by the research question: What is the impact of the COVID-19 pandemic on the university governance in Germany?

The study purposes were to investigate the effect of the COVID-19 pandemic on the university governance in Germany.

The qualitative study was implemented. The exploratory study was employed in the present work.

The interpretive research paradigm was used in the study. The interpretive paradigm is characterized by the researcher's practical interest in the research question (Cohen, Manion, \& Morrison, 2003). The interpretive paradigm is featured by the researcher's interest in a phenomenon. The interpretive paradigm is aimed at analysing the social construction of the meaningful reality. Meanings emerge from the interpretation. The researcher is the interpreter (Ahrens, Purvinis, Zaščerinska, Miceviciene, \& Tautkus, 2018).

The data were collected via the focus group interview. The focus group interview examined how knowledge, and more importantly, ideas, develop and operate within a given cultural context as well as explored exactly how the opinions were constructed (Kitzinger, 1995). A focus group usually includes from five to 10 participants (Krueger, 2002). The choice of participants for a focus 
group interview is conventionally based on three criteria (Zaščerinska, Aḷeksejeva, Aḷeksejeva, Gloṇina, Zaščerinskis, \& Andreeva, 2015):

- participant's knowledge on a given topic,

- participant's cultural difference, and education's diversity (scientific direction, occupation, training, etc), and

- $\quad$ participants' hierarchy in the group.

The number of participants depends on the heterogeneity of the focus group: the greater the heterogeneity of the group, the fewer the number of participants (Okoli \& Pawlovski, 2004). Further on, smaller groups show a greater potential (Krueger \& Casey, 2000) to examine the process of the construction of the knowledge and opinion.

The focus group interview was video-recorded, and detailed notes were made. The interview was relatively open and exploratory until novel concepts and ideas stop emerging. The full transcripts of the focus group interview were made, and the thematic analysis was carried out to elucidate common themes and topics of the discussion. The structuring content analysis was used to seek to assess the material according to the particular criteria that are strictly determined in advance (Mayring, 2004, p. 269). The summarizing content analysis seeks to reduce the material in such a way that the essential contents are preserved, but a manageable short text is produced (Mayring, 2004, p. 269).

\section{Empirical Study Results}

The focus group interview was carried out within the Forum of University Councils organised on the $22^{\text {nd }}$ September in Berlin, Germany. The Forum was entitled "Corona and the Consequences - What is next to Universities?".

The focus group was composed of about 30 respondents. The participants were

- university rectors, presidents and chancellors,

- representatives of State Ministry for Science,

- representatives of Germany Academic Exchange Service,

- university researchers, and

- university professors.

The focus group interview was based on the following questions:

- How is a university run in the times of crisis?

- How is the participation work organised in times of contact restrictions?

- How do the universities deliver the digital semester?

- Which positive developments can be expanded and perpetuated?

- How can politics best support universities in this situation?

- How and when can the international exchange be restarted? 
- What effects does the corona-related economic slump have on the university funding?

A respondent of the focus group interview stated that, in order to prepare universities to work in emergency situations, more focus should be put on the elaboration of a strategy, and not on defining separate actions.

Another respondent of the focus group interview agreed that by 2025 universities in Germany have to be able to practice hybrid (partly on campus and partly on-line) models in regard to teaching, learning, research and other activities.

In terms of teaching, a specific (professional) knowledge within a study programme will be delivered mostly on-line, while the knowledge for personal development of students - face-to-face. It was pointed that the preparation of a face-to-face lecture requires the same time as for the preparation of an on-line lecture. It was also noted that on-line lectures can be given by the university staff without the obligation for the teaching staff to do it from the university campus. On-line lectures can be delivered from any place and location.

Lectures for big students' groups were discussed to become on-line as the coronavirus pandemic restricted the number of participants per event. On-line lectures for big students' groups arise the problem of the use and management of big lecture halls in university buildings.

The transfer to the hybrid model of university studies increases the students' load. The respondents expressed the opinion that students' work within the university studies will only grow. As students' work within the university studies is tightly connected to students' learning, learning will take more and more an individual format. Individual learning will allow students' own pace within the university studies.

The delivery of lectures mostly on-line raised the issue of the use and management of university buildings. Currently, administrative staff members work in office rooms which are mostly occupied by one person. The respondents highlighted a possibility of creation of co-working spaces for administrative staff members at universities.

Another important issue that received a lot of attention was universities' internalization. The respondents opined that university internalization should be enhanced as internalisation facilitates the financing of studies and universities. The universities in Germany expect the increase of international team members after the introduction of the vaccine against coronavirus. The interview respondents pointed an interesting fact that during the first wave of the COVID-19 pandemic, more international students applied for an Erasmus+ exchange in Germany. The respondents assumed that the exchange students wished to stay in Germany during the first wave of the COVID-19 pandemic, despite Germany that time was on the list of the countries with a high infection rate, as Germany has a good health system that is highly ranked in Europe and worldwide. The interview 
respondents stressed that a new university ranking criteria such as a country's health system will appear in future.

University internalisation was also related to the university networking activities. Networking was concerned in a wider context, not only as part of university internalisation. The respondents underlined that a network cannot be established via digital tools, personal contacts and meetings are significant for the network creation and maintenance.

\section{Empirical Study Findings}

The analysis of the data collected through the focus group interview was based on the criterion, namely affairs/areas of university governance at institutional level.

The structuring content analysis allows finding that the most effected affairs/areas of university governance in Germany are

- Teaching:

- Mode such as face-to-face and on-line,

- Knowledge: specific and for personal development (soft skills),

- Teaching space such as lecture halls and on-line lectures,

- Learning:

- Individual format,

- Pace,

- Workload,

- University internalisation:

- International visitors,

- International networking,

- $\quad$ State health system,

- University administrative staff management:

- Office space

- University buildings' management:

- Big halls’ maintenance,

- University networking:

- Personal contacts.

It should be pointed that the respondents of the focus group interview highlighted that networking cannot be established without personal contacts and meetings. The respondents definitely considered teaching staff professional networks. In relation to university students, the university studies are an opportunity for students to start their own professional networking. Professional networking is also useful for group learning and peer learning that are found to be the necessary part of the students' study process (Zascerinska, 2013). However, 
the use of mostly digital tools for studies at university does not promote the establishment of a student's professional network. This allows finding that the student's study process has to include all the parts, namely teaching, peer learning and learning (Zascerinska, 2013).

The summarising content analysis allows identifying that the university governance in Germany has been externally affected at the institutional level. The emergency situation related to the COVID-19 pandemic has greatly impacted the university governance processes to be shifted in a short period of time

- from face-to face and hybrid

- to fully digital.

However, it should be pointed that hybrid studies at the universities in Germany were planned in advance and already partly introduced. The COVID-19 pandemic has only increased the pace as well as shortened the planned period of the time of the transformation, namely from face-to face and hybrid.

Along with the changing university governance processes, the COVID-19 global spread has an enormous influence on the re-elaboration and updating of university governance policies, rules and guidelines.

\section{Conclusions}

The theoretical finding is that the COVID-19 pandemic is a factor that influences the university governance. Further on, the COVID-19 pandemic is an external factor in regard to the university governance. Another theoretical finding is that the factor impact can be regulated. The factor impact can be increased or decreased according to the situation requirements.

The empirical findings reveal that changes in the university governance in Germany are in the full compliance with the university governance's shifts described in scientific literature. The empirical data allow concluding that the COVID-19 pandemic fastens the changes in governing the universities in Germany. For example, the introduction of the hybrid teaching and learning model was planned by 2025. The introduction of the hybrid teaching and learning model in Germany has already started, and the COVID-19 pandemic only speeded up this process. This leads to the conclusion that the university governance in Germany is well-planned and oriented to the sustainability of both, namely higher education and higher education institutions. The organisation of the Forum of German Universities' Councils implies that issues of the whole sector of higher education in Germany are being discussed and solved, and not the problems of each university. The university governance in Germany changes due to the COVID-19 pandemic effect. Another empirical finding is that Germany sets 2025 as the year of the introduction of the hybrid teaching and learning at universities. This discloses that the university governors in Germany concentrate on long-term issues and sustainability. Raising the issues of the relationship between higher 
education and state health system as well as the management of the university buildings makes evident that the university governors practise the approach of self-analysis from the informed perspective as these issues have not been investigated in scientific literature.

Implications for higher education have been formulated:

- $\quad$ the universities' governors are proposed to work together when dealing with the COVID-19 pandemic in particular in universities and in general in higher education,

- $\quad$ teaching in the study process at university has to be combined with peer learning in order to support the establishment of students' professional networks,

- $\quad$ students need face-to-face classes to start their professional networking in order to build and strengthen their professional capacity and competence,

- administrative premises have to be re-organised in accordance with the available space for working,

- $\quad$ the use of the university buildings and halls has to be re-structured,

- the university ranking system is to be updated with the state health system.

The present research has some limitations. A limitation is that the relationship only between the COVID-19 pandemic and the university governance has been set. Another limitation is that the empirical study was carried out only in one country, namely Germany. The group of respondents was limited by the participants of only one forum.

The further research will focus on identifying internal factors that influence the university governance. The list of external factors that influence the university governance will be extended. The future work will tend to increase the number and widen the groups and countries of respondents. The search for methods of data collection, analysis and interpretation is planned. Comparative studies of the impact of the COVID-19 on the university governance of different countries is also proposed.

\section{References}

Aboy, J. R. (2018). Report Chap. Retrieved from https://www.academia.edu/34571977/ REPORT_CHAP.

Ahrens, A., Purvinis, O., Zaščerinska, J., Micevičienė, D., \& Tautkus, A. (2018). Burstiness Management for Smart, Sustainable and Inclusive Growth: Emerging Research and Opportunities. IGI Global. DOI: 10.4018/978-1-5225-5442-4.

Cohen, L., Manion, L., \& Morrison, K. (2003). Research Methods in Education. London and New York: Routledge/Falmer Taylor \& Francis Group. 
Kitzinger, J. (1995). Education and debate Qualitative Research: Introducing focus groups. BMJ 1995; 311, 299-302

Krueger, R. A. \& Casey, M. A. (2000). Focus Groups: A Practical Guide for Applied Research, 3rd ed. Thousand Oaks, CA: Sage Publications.

Mayring, P. (2004). Qualitative Content Analysis. In: U. Flick, E. Von Kardoff and I. Steinke (Eds). A Companion to Qualitative Research (pp. 266-269). SAGE.

McVitty, D. (2020). From crisis to creativity: how Covid-19 could change HE governance posted on 06/05/2020. Retrieved from https://wonkhe.com/blogs/from-crisis-tocreativity-how-covid-19-could-change-he-governance/.

Okoli, C., \& Pawlovski, S. (2004). The Delphi Method as a Research Tool: an example, design considerations and applications. Information and Management, 42(1), 15-29.

Peregrine, M.W., DeJong, R., DiVarco, S., McDermott, W., \& Emery, LLP. (2020). The LongTerm Impact of the Pandemic on Corporate Governance, posted on Thursday, July 16, 2020. Retrieved from https://corpgov.law.harvard.edu/2020/07/16/the-long-term-impactof-the-pandemic-on-corporate-governance/

Shattock, M. (2006). Managing good governance in higher education. Open University Press, Berkshire.

Zaščerinska, J. (2013). Development of Students' Communicative Competence within English for Academic Purposes Studies. Verlag: Mensch \& Buch.

Zaščerinska, J., Aḷeksejeva, A., Aḷeksejeva, L., Gloṇina, O., Zaščerinskis, M., \& Andreeva, N. (2015). Formal Adult Education in Latvia: Focus Group Interview. In O. Clipa \& G. Cramariuc (eds.), Educatia in societatea contemporana. Aplicatii (pp. 287-294). Iasi, Romania: Editura LUMEN. Retrieved from http://edituralumen.ro/english/wpcontent/proceedings/ECS_LUMEN2015_Proceedings.pdf.

Zaščerinska, J., Zaščerinskis, M., Andreeva, N., \& Aḷeksejeva, L. (2013). Factors that Influence the Educational process. International Journal of Modern Education Forum (IJMEF) Volume 2, Issue 3 (August 2013), pp. 57-65. Retieved from http://www.ijmef.org/ AllIssues.aspx. 